\title{
Intersection Measurement for Rotatable Arc Guideway System
}

\author{
Kaixin Cui ${ }^{1}$, Shunqing Ren ${ }^{1, *}$, Jinru Yuan ${ }^{2}$ and Yikang Liu ${ }^{1}$ \\ ${ }^{1}$ Space Control and Inertial Technology Research Center, Harbin Institute of Technology, Harbin 150001, China \\ ${ }^{2}$ Shanghai Institute of Satellite Engineering, Shanghai, 200240, China \\ ${ }^{*}$ Corresponding author
}

\begin{abstract}
In order to measure the intersection of rotatable arc guideway system, namely, the distance from the center determined by the rotatable arc guideway to the axis line of rotation, a crosshair target was fixed on the slider sliding along the arc guideway, and a theodolite was installed in the front of the rotatable arc guideway system. Horizontal angles and vertical angles of the theodolite, which directed to the crosshair target sliding on different positions of the guideway while in $0^{\circ}$ and $180^{\circ}$ positions of the axis system, were acquired. The coordinates of the target on the theodilite coordinate frame were achieved by homogeneous transformation method, the relationships among the readouts of the theodolite, target's coordinates, some position and attitude errors, the distance between the theodolite and center of the arc guideway were established, by way of linearization and iterated least square method, the arc centers in $0^{\circ}$ and $180^{\circ}$ angular positions were calculated and then the intersection was attained finally. By simulating the measurement process with two semi-circles, the intersection measurement value is consistent with the practical setting value, it is proved that the proposed method is correct.
\end{abstract}

Keywords—rotatable arc guideway; intersection; theodolite; homogeneous transformation; iterated least square method

\section{INTRODUCTION}

References [1 3] use the objective motion simulator to simulate the actual moving objective, and its performance will directly affect the reliability of the simulation results of missile or radar. The simulator, which is a multi-body system, is composed of a moving slider, a rotatable arc guideway and a rotating axis system. The moving objective is fixed on the slider, the slider slides along the arc guideway, and the whole arc guideway can rotate about the axis line of rotation. In order to ensure the location accuracy of moving objective in space, we need to ensure that the arc center determined by the trajectory of moving objective sliding along the rotatable arc guideway is on the axis line of rotation. The distance from the center of the arc to the axis line of rotation is defined as intersection.

The specification for intersection is required in the threeaxis turntable, the two-axis turntable and the five-axis simulator, and the measurement of the intersection also has a certain method. References [4 6] use the micrometer, the dial gauge, the theodolite and other measuring instruments to lead to the points on the axis lines and then the intersection is measured. Reference [7] uses the dial gage leads to the points of axis in two parallel states, and then the intersection is measured.
References [8 10] use the crosshair target to lead to the points on the axis lines, then the axis lines are led to by two crosshair targets, later on the axis intersection is acquired through the positional relationships among these axis lines. References [11 13] have put forward an axis intersection measurement method for three-axis turntable with a filament. Reference [14] presents a measurement method of perpendicularity, axis intersection, alignment error of five-axis simulator by using the least square method to fit the arc center of crosshair target's locus.

The intersection described in this paper is a description of whether the center of the circular- arc is on the axis line of rotation. The measurement principle is expounded as follows.

\section{THE AXIS INTERSECTION OF ROTATABLE ARC GUIDEWAY}

Objective motion simulator is shown in Figure I. The rotatable arc guideway and a rotating axis are fixed rigidly, the motion objective is mounted on the slider, and the slider can be controlled by the motor to slide along the arc guideway, and the whole arc guideway can rotate about the rotating axis line. To measure the intersection, a crosshair target is fixed on the slider. Ideally, the arc center determined by the trajectory of crosshair target sliding along the arc guideway should be on the rotating axis line. However, the actual arc center often has a certain distance from the axis line. The distance from arc center $O$ to rotating axis line $A B$ is defined as the intersection of the rotatable arc guideway.

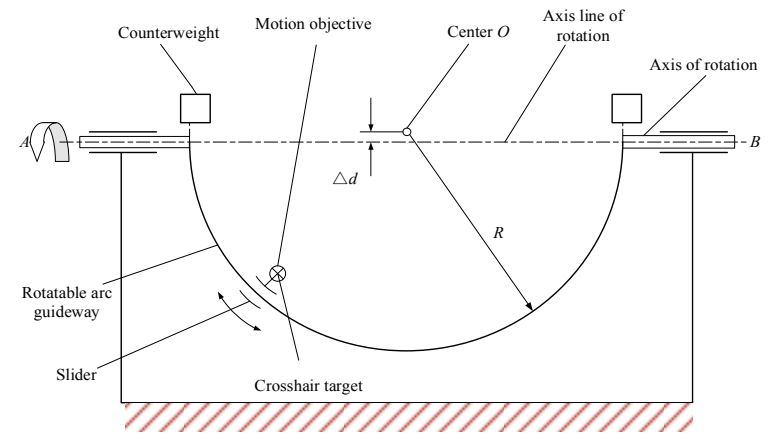

FIGURE I. SKETCH MAP OF MOTION OBJECTIVE SIMULATOR 


\section{INTERSECTION MEASUREMENT FOR ROTATABLE ARC GUIDEWAY SYSTEM}

A theodolite is used to measure the intersection of the motion simulator of rotatable arc guideway, and the sketch map of measurement method is shown in Figure II. Firstly, the horizontal axis is controlled at $0^{\circ}$ while the locus of the slider is in the vertical plane, and the theodolite is placed in front of the rotatable arc guideway. Secondly, a crosshair target is fixed on the slider. When the crosshair target moves along the circular rail to a certain position, the theodolite directed to the target, and its horizontal angles and vertical angles are recorded. Finally, arc center position $O_{1}$ of the upper semi-circle guideway can be identified by the iterated least square method.

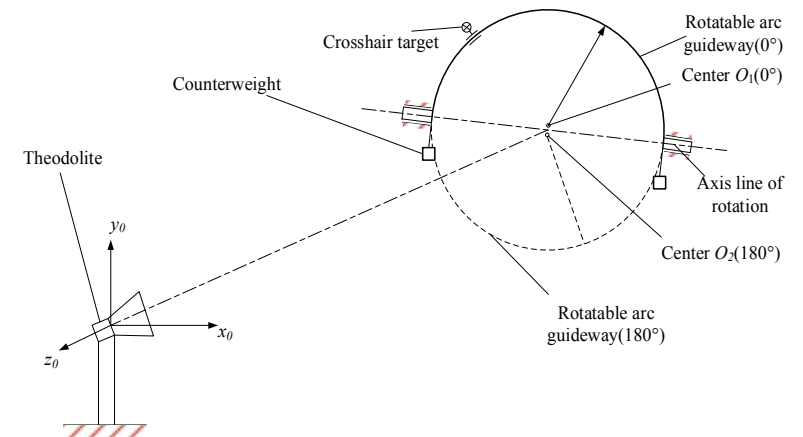

FIGURE II. MEASUREMENT SYSTEM FOR THE INTERSECTION OF THE ROTATABLE ARC GUIDEWAY

Then, the angular position of rotating axis system is controlled at $180^{\circ}$, the other crosshair target is also fixed on the slider. The trajectory of crosshair target is below the axis line and is also in vertical plane. Similarly, recording the horizontal angles and vertical angles of the theodolite and identifying arc center position $\mathrm{O}_{2}$ of the lower semi-circle guideway. Apparently, half of the distance between $O_{1}$ and $O_{2}$ is the intersection of the rotatable arc guideway system.

The origin of the reference coordinate frame $o_{0} x_{0} y_{0} z_{0}$ is the center of theodolite. The theodolite's telescope axis is defined as $o_{0} z_{0}$ axis when it points to and is perpendicular to the vertical trajectory plane of the slider sliding along arc guideway, the $o_{0} x_{0}$ axis is consistent with the horizontal axis of the theodolite and $o_{0} y_{0}$ axis points upwards. When the reference coordinate frame is set up, it is assumed that the horizontal and vertical angles of the theodolite are $\alpha_{0}$ and $\beta_{0}$ respectively. The origin of the coordinate frame $o_{1} x_{1} y_{1} z_{1}$ is located at the center of arc guideway. The coordinate of $O_{1}$ in the reference coordinate frame is $(\Delta x, \Delta y,-L)$, where $\mathrm{L}$ is the distance from the center of the theodolite to the vertical plane determined by the trajectory of crosshair target while the guideway in the initial position. There is a small threedimensional attitude error $\left(\Delta \theta_{x}, \Delta \theta_{y}, \Delta \theta_{z}\right)$ between the coordinate system $o_{1} x_{1} y_{1} z_{1}$ and $o_{0} x_{0} y_{0} z_{0}$. Assuming that the coordinate of crosshair target is expressed as $\left(x_{i}, y_{i}, 0\right)$ under the coordinate frame $o_{1} x_{1} y_{1} z_{1}$, then, the homogeneous coordinates of the crosshair target in the reference coordinate frame are as follows:

$$
\left[\begin{array}{cccc}
1 & 0 & 0 & \Delta x \\
0 & 1 & 0 & \Delta y \\
0 & 0 & 1 & -L \\
0 & 0 & 0 & 1
\end{array}\right]\left[\begin{array}{cccc}
1 & -\Delta \theta_{z} & \Delta \theta_{y} & 0 \\
\Delta \theta_{z} & 1 & -\Delta \theta_{x} & 0 \\
-\Delta \theta_{y} & \Delta \theta_{x} & 1 & 0 \\
0 & 0 & 0 & 1
\end{array}\right]\left[\begin{array}{c}
x_{i} \\
y_{i} \\
0 \\
1
\end{array}\right]=\left[\begin{array}{c}
\Delta x-\Delta \theta_{z} y_{i}+x_{i} \\
\Delta y+y_{i}+\Delta \theta_{z} x_{i} \\
-L-\Delta \theta_{y} x_{i}+\Delta \theta_{x} y_{i} \\
1
\end{array}\right]
$$

According to the above narration and the working principle of theodolite, the horizontal angle and vertical angle of theodolite aligning to the crosshair target are $\alpha_{i}$ and $\beta_{i}$, when the target moves to a certain position $i$ along the arc guideway.

Then:

$$
\begin{gathered}
\tan \left(\alpha_{i}-\alpha_{0}\right)=\frac{\Delta x-\Delta \theta_{z} y_{i}+x_{i}}{L+\Delta \theta_{y} x_{i}-\Delta \theta_{x} y_{i}} \\
\tan \left(\beta_{i}-\beta_{0}\right)=\frac{\Delta y+y_{i}+\Delta \theta_{z} x_{i}}{L+\Delta \theta_{y} x_{i}-\Delta \theta_{x} y_{i}}
\end{gathered}
$$

So,

$$
\begin{aligned}
& x_{i}=-\Delta x+\Delta \theta_{z} y_{i}+L \tan \left(\alpha_{i}-\alpha_{0}\right)+\left(\Delta \theta_{y} x_{i}-\Delta \theta_{x} y_{i}\right) \tan \left(\alpha_{i}-\alpha_{0}\right) \\
& y_{i}=-\Delta y+\Delta \theta_{z} x_{i}+L \tan \left(\beta_{i}-\beta_{0}\right)+\left(\Delta \theta_{y} x_{i}-\Delta \theta_{x} y_{i}\right) \tan \left(\beta-\beta_{0}\right)
\end{aligned}
$$

As the trajectory of the crosshair target is semi-circle, the initial measurement value of the radius of this arc is $R_{0}$ and the true radius is $R_{0}+\Delta R$, and the constraint conditions should be satisfied for formula (6):

$$
x_{i}^{2}+y_{i}^{2}=\left(R_{0}+\Delta R\right)^{2}
$$

From formulae (4) and (5):

$$
\begin{gathered}
x_{i}^{2}+y_{i}^{2}=L^{2} \tan ^{2}\left(\alpha_{i}-\alpha_{0}\right)+L^{2} \tan ^{2}\left(\beta_{i}-\beta_{0}\right)-2\left(\Delta x-\Delta \theta_{z} y_{i}\right) L \tan \left(\alpha_{i}-\alpha_{0}\right) \\
+2\left(\left(\Delta \theta_{y} x_{i}-\Delta \theta_{x} y_{i}\right)\right) L \tan ^{2}\left(\alpha_{i}-\alpha_{0}\right)-2 L\left(\Delta y+\Delta \theta_{z} x_{i}\right) \tan \left(\beta_{i}-\beta_{0}\right) \\
-2\left(\Delta \theta_{y} x_{i}-\Delta \theta_{x} y_{i}\right) L \tan ^{2}\left(\beta_{i}-\beta_{0}\right)
\end{gathered}
$$

The initial coordinates of each point are obtained as follows: $x_{i} \approx L \tan \left(\alpha_{i}-\alpha_{0}\right), y_{i} \approx L \tan \left(\beta_{i}-\beta_{0}\right), \Delta x=0, \Delta y=0, \Delta \theta_{x}=0$, $\Delta \theta_{y}=0, \Delta \theta_{z}=0$, Substituting formula (7) into (6), after data 
reduction and neglecting the second-order small quantities, formula (8) is obtained:

$$
\begin{gathered}
R_{0}^{2}-x_{i}^{2}-y_{i}^{2}=-2 R_{0} \Delta R-2 \Delta x \cdot x_{i}+2 \Delta \theta_{y} x_{i}^{2} \tan \left(\alpha_{i}-\alpha_{0}\right) \\
-2 \Delta \theta_{x} y_{i} x_{i} \tan \left(\alpha_{i}-\alpha_{0}\right)-2 \Delta y \cdot y_{i}-2 \Delta \theta_{y} x_{i} \cdot y_{i} \tan \left(\beta_{i}-\beta_{0}\right) \\
+2 \Delta \theta_{x} y_{i}^{2} \tan \left(\beta_{i}-\beta_{0}\right)
\end{gathered}
$$

It is easy to find that $\Delta \theta_{z}$ does not appear in formula (8), because it does not affect the constraint condition, and the formula (8) can be rewritten in the form of a matrix:

$$
y=\Phi K+\varepsilon
$$

Where, $\varepsilon$ is residual error vector,

$$
\boldsymbol{\Phi}=\left[\begin{array}{ccccc}
-2 R_{0} & -2 x_{1} & -2 y_{1} & \Phi_{14} & \Phi_{15} \\
-2 R_{0} & -2 x_{2} & 2 y_{2} & \Phi_{24} & \Phi_{25} \\
\mathrm{M} & \mathrm{M} & \mathrm{M} & \mathrm{M} & \mathrm{M} \\
-2 R_{0} & -2 x_{n} & 2 y_{n} & \Phi_{n 4} & \Phi_{n 5}
\end{array}\right]
$$

Where,

$$
\begin{aligned}
& \Phi_{i 4}=2 y_{i}^{2} \tan \left(\beta_{i}-\beta_{0}\right)-2 x_{i} y_{i} \tan \left(\alpha_{i}-\alpha_{0}\right) \\
& \Phi_{i 5}=2 x_{i}^{2} \tan \left(\alpha_{i}-\alpha_{0}\right)-2 x_{i} y_{i} \tan \left(\beta_{i}-\beta_{0}\right) \\
& \boldsymbol{K}=\left[\begin{array}{lllll}
\Delta R & \Delta x & \Delta y & \Delta \theta_{x} & \Delta \theta_{y}
\end{array}\right]^{\mathrm{T}} \\
& \boldsymbol{y}=\left[\begin{array}{l}
R_{0}^{2}-L^{2} \tan ^{2}\left(\alpha_{1}-\alpha_{0}\right)-L^{2} \tan ^{2}\left(\beta_{1}-\beta_{0}\right) \\
R_{0}^{2}-L^{2} \tan ^{2}\left(\alpha_{2}-\alpha_{0}\right)-L^{2} \tan ^{2}\left(\beta_{2}-\beta_{0}\right) \\
R_{0}^{2}-L^{2} \tan ^{2}\left(\alpha_{n}-\alpha_{0}\right)-L^{2} \tan ^{2}\left(\beta_{n}-\beta_{0}\right)
\end{array}\right]
\end{aligned}
$$

The least square estimation of $\boldsymbol{K}$ is:

$$
\hat{\boldsymbol{K}}=\left(\boldsymbol{\Phi}^{\mathrm{T}} \boldsymbol{\Phi}\right)^{-1} \boldsymbol{\Phi}^{\mathrm{T}} \boldsymbol{y}
$$

$R_{0}+\Delta R$ is set as a new $R_{0}$, and $\Delta x+K(2), \Delta y+K(3)$, $\Delta \theta_{x}+K(4)$ and $\Delta \theta_{y}+K(5)$ are set as new $\Delta x, \Delta y, \Delta \theta_{x}$ and $\Delta \theta_{y}$, which are iterated over and over again until the precision requirement is met.
Finally, the value of $K(3)$ is the ordinate $\Delta y$ of the arc center $O_{1}$. After the horizontal axis line rotating to $180^{\circ}$, the new data are replaced, and the same method is used to resolve the ordinate $\Delta y^{\prime}$ of the arc center $O_{2}$. The intersection of the rotatable arc guideway is as follows:

$$
\Delta d=\frac{\Delta y-\Delta y^{\prime}}{2}
$$

The simulation measurement of a rotatable arc guideway's intersection is carried out. The practical map of simulation measurement is shown in Figure III, and the measurement points are shown in Figure IV. In Figure IV, the distance between the centers of the two semi-circles is setting to $4 \mathrm{~mm}$, the equivalent of the intersection of the rotatable arc guideway is $2 \mathrm{~mm}$. The trajectory of the upper half section is in $0^{\circ}$ position and the trajectory of the lower half section is in $180^{\circ}$ position. During the measurement process, 17 positions were selected on both the upper and the lower segments.

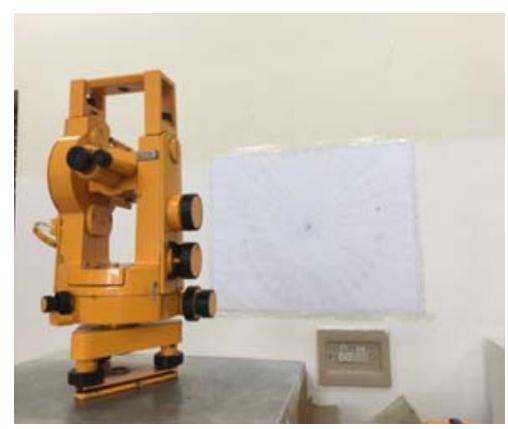

FIGURE III. PRACTICAL MAP OF SIMULATION MEASUREMENT

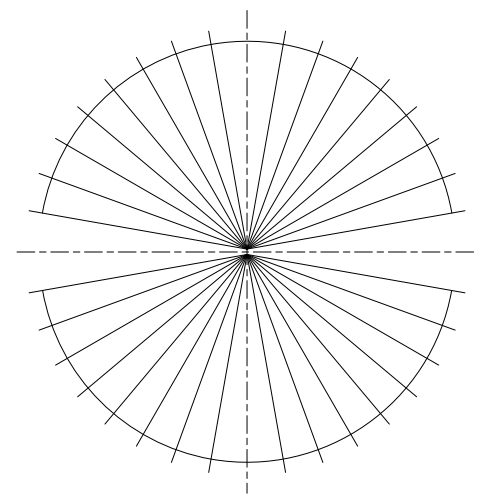

FIGURE IV. MEASUREMENT POINTS

A theodolite is used to measure the horizontal and vertical angles of a crosshair target moving to different positions, the results are shown in Table I. For the upper half arc guideway, the initial horizontal angle and vertical angle of the theodolite are $\alpha_{0}=332^{\circ} 32^{\prime} 54^{\prime \prime}$ and $\beta_{0}=89^{\circ} 59^{\prime} 57^{\prime \prime}$; For the lower half arc guideway, the initial horizontal angle and vertical angle are $\alpha_{0}=332^{\circ} 32^{\prime} 50^{\prime \prime}$ and $\beta_{0}=89^{\circ} 59^{\prime} 58^{\prime \prime}$. 
TABLE I. HORIZONTAL ANGLES AND VERTICAL ANGLES OF CROSSHAIR TARGET $(L=2405 \mathrm{MM})$

\begin{tabular}{|c|c|c|c|c|}
\hline \multirow[b]{2}{*}{$\begin{array}{c}\text { Number } \\
i\end{array}$} & \multicolumn{2}{|c|}{$\begin{array}{c}\text { Axis line position } \\
0^{\circ}\end{array}$} & \multicolumn{2}{|c|}{$\begin{array}{c}\text { Axis line position } \\
180^{\circ}\end{array}$} \\
\hline & $\begin{array}{l}\text { Horizontal } \\
\text { angles } \alpha_{i}\end{array}$ & $\begin{array}{c}\text { Vertical } \\
\text { angles } \beta_{i}\end{array}$ & $\begin{array}{c}\text { Horizontal } \\
\text { angles } \alpha_{i}\end{array}$ & $\begin{array}{l}\text { Vertical } \\
\text { angles } \beta_{i}\end{array}$ \\
\hline 1 & $341^{\circ} 52^{\prime} 24^{\prime \prime}$ & $88^{\circ} 16^{\prime} 49^{\prime \prime}$ & $341^{\circ} 55^{\prime} 22^{\prime \prime}$ & $91^{\circ} 34^{\prime} 53^{\prime \prime}$ \\
\hline 2 & $341^{\circ} 26^{\prime} 01^{\prime \prime}$ & $86^{\circ} 41^{\prime} 24^{\prime \prime}$ & $341^{\circ} 31^{\prime} 06^{\prime \prime}$ & $93^{\circ} 11^{\prime} 32^{\prime \prime}$ \\
\hline 3 & $340^{\circ} 44^{\prime} 00^{\prime \prime}$ & $85^{\circ} 11^{\prime} 45^{\prime \prime}$ & $340^{\circ} 50^{\prime} 00^{\prime \prime}$ & $94^{\circ} 42^{\prime} 11^{\prime \prime}$ \\
\hline 4 & $339^{\circ} 47^{\prime} 00^{\prime \prime}$ & $83^{\circ} 50^{\prime} 34^{\prime \prime}$ & $339^{\circ} 53^{\prime} 47^{\prime \prime}$ & $96^{\circ} 04^{\prime} 29^{\prime \prime}$ \\
\hline 5 & $338^{\circ} 36^{\prime} 36^{\prime \prime}$ & $82^{\circ} 40^{\prime} 39^{\prime \prime}$ & $338^{\circ} 44^{\prime} 15^{\prime \prime}$ & $97^{\circ} 16^{\prime} 03^{\prime \prime}$ \\
\hline 6 & $337^{\circ} 14^{\prime} 41^{\prime \prime}$ & $81^{\circ} 44^{\prime} 12^{\prime \prime}$ & $337^{\circ} 23^{\prime} 37^{\prime \prime}$ & $98^{\circ} 14^{\prime} 26^{\prime \prime}$ \\
\hline 7 & $335^{\circ} 44^{\prime} 03^{\prime \prime}$ & $81^{\circ} 02^{\prime} 35^{\prime \prime}$ & $335^{\circ} 53^{\prime} 17^{\prime \prime}$ & $98^{\circ} 57^{\prime} 26^{\prime \prime}$ \\
\hline 8 & $334^{\circ} 07^{\prime} 17^{\prime \prime}$ & $80^{\circ} 37^{\prime} 16^{\prime \prime}$ & $334^{\circ} 16^{\prime} 13^{\prime \prime}$ & $99^{\circ} 24^{\prime} 22^{\prime \prime}$ \\
\hline 9 & $332^{\circ} 27^{\prime} 38^{\prime \prime}$ & $80^{\circ} 29^{\prime} 30^{\prime \prime}$ & $332^{\circ} 35^{\prime} 58^{\prime \prime}$ & $99^{\circ} 34^{\prime} 22^{\prime \prime}$ \\
\hline 10 & $330^{\circ} 48^{\prime} 15^{\prime \prime}$ & $80^{\circ} 38^{\prime} 28^{\prime \prime}$ & $330^{\circ} 55^{\prime} 49^{\prime \prime}$ & $99^{\circ} 26^{\prime} 25^{\prime \prime}$ \\
\hline 11 & $329^{\circ} 12^{\prime} 04^{\prime \prime}$ & $81^{\circ} 05^{\prime} 01^{\prime \prime}$ & $329^{\circ} 18^{\prime} 18^{\prime \prime}$ & $99^{\circ} 01^{\prime} 24^{\prime \prime}$ \\
\hline 12 & $327^{\circ} 42^{\prime} 01^{\prime \prime}$ & $81^{\circ} 47^{\prime} 34^{\prime \prime}$ & $327^{\circ} 47^{\prime} 04^{\prime \prime}$ & $98^{\circ} 19^{\prime} 19^{\prime \prime}$ \\
\hline 13 & $326^{\circ} 20^{\prime} 49^{\prime \prime}$ & $82^{\circ} 45^{\prime} 13^{\prime \prime}$ & $326^{\circ} 24^{\prime} 45^{\prime \prime}$ & $97^{\circ} 22^{\prime} 42^{\prime \prime}$ \\
\hline 14 & $325^{\circ} 11^{\prime} 34^{\prime \prime}$ & $83^{\circ} 56^{\prime} 30^{\prime \prime}$ & $325^{\circ} 14^{\prime} 02^{\prime \prime}$ & $96^{\circ} 11^{\prime} 59^{\prime \prime}$ \\
\hline 15 & $324^{\circ} 15^{\prime} 32^{\prime \prime}$ & $85^{\circ} 18^{\prime} 20^{\prime \prime}$ & $324^{\circ} 16^{\prime} 19^{\prime \prime}$ & $94^{\circ} 50^{\prime} 39^{\prime \prime}$ \\
\hline 16 & $323^{\circ} 34^{\prime} 38^{\prime \prime}$ & $86^{\circ} 48^{\prime} 59^{\prime \prime}$ & $323^{\circ} 33^{\prime} 54^{\prime \prime}$ & $93^{\circ} 20^{\prime} 30^{\prime \prime}$ \\
\hline 17 & $323^{\circ} 10^{\prime} 29^{\prime \prime}$ & $88^{\circ} 25^{\prime} 21^{\prime \prime}$ & $323^{\circ} 07^{\prime} 41^{\prime \prime}$ & $91^{\circ} 44^{\prime} 12^{\prime \prime}$ \\
\hline
\end{tabular}

The intersection of the rotatable arc guideway is identified according to the above-mentioned method. For the upper half arc guideway, namely in $0^{\circ}$ position, $\Delta R=-0.0091 \mathrm{~mm}$. It means that the identification of radius is $399.991 \mathrm{~mm}$. At the same time, $\Delta x=-0.972 \mathrm{~mm}, \Delta y=1.8143 \mathrm{~mm}, \Delta \theta_{x}=2.8 \times 10^{-5} \mathrm{rad}=5.8^{\prime \prime}$, $\Delta \theta_{y}=-3.9 \times 10^{-5} \mathrm{rad}=-8.1^{\prime \prime}$; For the lower half arc guideway, namely in $180^{\circ}$ position, $\Delta R=-0.0318 \mathrm{~mm}$. It means that the identification of radius is $399.968 \mathrm{~mm}$. And $\Delta x=-1.492 \mathrm{~mm}$, $\Delta y=-2.054 \mathrm{~mm}, \Delta \theta_{x}=3.6 \times 10^{-5} \mathrm{rad}=7.4^{\prime \prime}, \Delta \theta_{y}=-1.7 \times 10^{-5} \mathrm{rad}=-3.5^{\prime \prime}$. Therefore, the intersection $\Delta d$ of the rotatable arc guideway system is $(1.8143-(-2.0538)) / 2=1.934 \mathrm{~mm}$. The setting intersection is $2 \mathrm{~mm}$, and the difference is $0.066 \mathrm{~mm}$. The accuracy requirement for measuring the intersection of the rotatable arc guideway is achieved.

\section{CONCLUSION}

This paper presents a method for measuring the intersection of the rotatable arc guideway system. Firstly, the relationships among the motion objective coordinates at different positions on the rotatable arc guideway, and horizontal angles and vertical angles of the theodolite while aligning the crosshair target, have been deduced by using homogeneous transformation method. Then, by utilizing the constraint conditions, the iterated least square method for fitting arc center coordinate determined by the trajectory of moving target has been deduced. Finally, the correctness and reliability of the algorithm are verified by the simulation measurement.

\section{REFERENCES}

[1] JIN Guangzai, ZHU Feng, XU Jihe. Research on the Motion Control System for Arc-track Target Simulator[J]. Mechanical and Electronics, 2015(1):57-60.

[2] WU Yonggang, LV Junjie. Analysis of the existing infrared target simulator[J]. Journal of System Simulation, 1993,5(4):27-30.

[3] ZHNAG Xiantong, LIU Yazhong, LIANG Yingchun. The Mechanical Structure Scheme Analysis and Key Technique[J]. Journal of Chinese Inertial Technology, 1996,4(4):75-77.

[4] Zhang Qingchun, Ling Yingchun, Zhang Xiantong, etc. Research on Measurement of Axes Intersection Errors of Three-Axis Test Table[J]. Journal of Chinese Inertial Technology, 1996,4(3):82-84.
[5] YU Zhijing, SUN Hailong, TAO Hongwei, etc. New Measurement Method of Axes Intersection and Perpendicularity of Three-axis Test Table[J]. Machine tools and hydraulics, 2015,43(17):24-28.

[6] WANG Ming-yuan, YANG Lian-chun, YU Hai-sheng, etc. A three-axis Intersecting Degree Measurement[J]. Journal of Astronautic Metrology and Measurement, 2012,32(2):15-17.

[7] Ren Shunqing, Chen Shijia, Li Yuhua. Axis Intersection Measurement of Three-axis Turntable with Dial Gauge[J]. Tool technology, 2003,37(2):49-51.

[8] Ren S Q, Ma G C, Wang C H. Axis intersection measurement of threeaxis turntable with two crosshair targets[J]. Journal of Harbin Institute of Technology, 2005,12(3):250-254.

[9] REN Shunqing, FANG Zhenyong. WU Guangyu. Intersection Measuring Technique of Axis Lines in Two Orthogonal Axis Systems[J]. Journal of Chinese Inertial Technology, 1999,7(1):62-65.

[10] Cao Yunlong, Gao Kang, Ren Shunqing. Axis Line Intersection Measurement Method of Small Three-axis Turntable[J]. Tool technology, 2016,50(12):93-95.

[11] Ren Shunqing, Zeng Qingshuang, Yang Qihui. Axis intersection measurement of three-axis turntable with one filament[J]. China Mechanical Engineering, 2002,13(15):1310-1313.

[12] Ren Shunqing, Li Shunli, Fang Zhenyong. Axis intersection measurement of two-axis turntable with two filaments[J]. Modern manufacturing engineering, 2002(4):38-40.

[13] WU Mengxuan, LIU Qingbo, REN Shunqing. Method for measuring axis line intersection of three-axis turntable without luminous hole at the ends of shaft[J]. CHINA MEASUREMENT \& TEST, 2017,43(1):13-16.

[14] REN Shunqing, GAO Kang, ZHAO Hongbo. Measurement method of perpendicularity, axis intersection, alignment error of five-axis simulator[J]. Journal of Harbin Institute of Technology, 2015,47(10):1-6. 